\title{
Five Strand Hamstring Tendon Autograft for Anterior Cruciate Ligament Reconstruction Provides No Benefit over the Gold Standard Four Strand Repair for Anterior Stability of the Knee: A Prospective Cohort Study
}

\author{
A. Sideris ${ }^{1,2,3}$, A. Hamze', N. Bertollo1, D. Broe ${ }^{1,2,3}$, WR Walsh ${ }^{1,2,3}$ \\ ${ }^{1}$ Surgical and Orthopaedic Research Laboratories, Prince of Wales Hospital, Randwick, New South Wales, Australia \\ ${ }^{2}$ Prince of Wales Clinical School, UNSW Medicine, University of New South Wales, Randwick, New South Wales, Australia \\ ${ }^{3}$ Prince of Wales Orthopaedic Department, Prince of Wales Hospital, Randwick, New South Wales, Australia \\ Email: anders.sideris@gmail.com
}

How to cite this paper: Sideris, A., Hamze, A., Bertollo, N., Broe, D. and Walsh, W. (2017) Five Strand Hamstring Tendon Autograft for Anterior Cruciate Ligament Reconstruction Provides No Benefit over the Gold Standard Four Strand Repair for Anterior Stability of the Knee: A Prospective Cohort Study. Open Journal of Orthopedics, 7, 156-172.

https://doi.org/10.4236/ojo.2017.76018

Received: May 11, 2017

Accepted: June 25, 2017

Published: June 28, 2017

Copyright $\odot 2017$ by authors and Scientific Research Publishing Inc. This work is licensed under the Creative Commons Attribution International License (CC BY 4.0).

http://creativecommons.org/licenses/by/4.0/

\begin{abstract}
The Four-Strand Hamstring Tendon Autograft has been long established as the gold standard for surgical reconstruction of the Anterior Cruciate Ligament. Some studies have suggested wider grafts, such as a Five-Strand hamstring graft, may provide greater strength and a larger scaffold for incorporation of the graft into the bone tunnels, leading to greater postoperative anterior stability of the knee. 28 ( $n=18$ Four-Strand and $n=10$ Five-Strand) patients with planned ACL reconstructive surgery by a single surgeon were recruited for this study. The KT-1000 Arthrometer (MED metric, CA, USA) was used to quantify AP translation in the subjects' knees before (T0) and after surgery at 6 (T1) and 12 (T2) weeks. At 12 weeks there was significantly higher $(\mathrm{p}=0.01)$ mean anterior laxity on Maximum Manual Test in the FiveStrand group $(9.1 \pm 1.7 \mathrm{~mm})$ than the Four Strand Group $(6.9 \pm 2.3 \mathrm{~mm})$. Further, there were significantly higher mean side-to-side differences $(\mathrm{p}=$ $0.01)$ on Maximum Manual Test in the Five-Strand cohort $(5.1 \pm 3.5 \mathrm{~mm})$ compared to the Four-Strand cohort $(1.9 \pm 2.2 \mathrm{~mm})$. A significantly larger positive mean change in anterior laxity $(\mathrm{p}=0.02)$ from 6 - 12 weeks was evident in the Five-Strand group $(1.4 \pm 0.9)$ than the Four-Strand group $(-0.3 \pm$ $1.9 \mathrm{~mm})$. No significant correlations were seen between graft widths and measures of anterior stability on KT-1000. This study illustrated that there was no benefit to using a Five-Strand Hamstring Tendon Autograft when compared to the gold standard Four-Strand Repair specifically with regards to anterior stability of the knee.
\end{abstract}




\section{Keywords}

Anterior Cruciate Ligament, ACL, Anterior Cruciate Ligament Reconstructive Surgery, Anterior Cruciate Ligament Reconstruction, ACL Reconstruction, Five Strand Hamstring Tendon Autograft, Four Strand Hamstring Tendon Autograft, KT-1000, AP Translation, Knee

\section{Introduction}

The goal of Anterior Cruciate Ligament (ACL) Reconstructive Surgery is to restore the stability of the knee to pre-injury function. Degenerative arthritis is a common long-term consequence of ACL reconstruction and has been linked to derangements in antero-posterior stability of the knee. The width of the autograft used for reconstruction is relevant for the mechanical strength, the percentage restoration of the native anatomical footprint and optimising tendon bone healing such that clinical stability of the knee can be optimised postoperatively. The current gold standard is the Four-Strand Hamstring Tendon Autograft. A wider autograft construct may be beneficial for post-operative knee stability by providing a more robust intra-articular graft.

Hamner et al (1999) illustrated a strong positive correlation $\left(R^{2}=0.996\right)$ between number of strands in the hamstring tendon autograft and maximum load to failure [1]. Middleton et al (2014) showed in a case series of 45 patients that commonly used grafts for single bundle ACL reconstruction did not completely restore the native femoral and tibial footprints. The average percentage of reconstructed area was $79 \% \pm 13 \%$ for the femoral side, and $70 \% \pm 12 \%$ for the tibial side [2]. Another study quoted the percentage of the femoral footprint covered by tunnels in cadavers to be $53.97 \%+/-7.78 \%$ [3]

Robinson et al (2009) compared the coverage of the anatomical footprint for different sizes of graft $(6,9$ and $12 \mathrm{~mm})$. Increased width from 6 to $12 \mathrm{~mm}$ equated to an increase in coverage of the native ACL footprint from $14.7 \%$ to $58.7 \%$ for the tibial and $14.9 \%$ to $59.4 \%$ at the femoral end. Increase in graft diameter was noted to restore a larger percentage of both the anteromedial and posterolateral bundles, more effectively restoring the native tensioning patterns of each bundle. The 6, 9 and $12 \mathrm{~mm}$ grafts captured an average of 32\%, 51\% and $66 \%$ of the length change behaviour of the native ACL in the flexion cycle, with an increasing number of lateral AM fibres and central and medial PL fibres being recruited as the graft width increased, suggesting larger autograft width more effectively replicated the function of the native ACL [4].

Westermann et al (2013) used a non-linear contact finite element model based on cadaveric data to evaluate the relationship between ACL graft size and knee joint laxity, meniscal stress, in situ graft loading, and peak articular cartilage contact pressure for graft sizes ranging from $5-9 \mathrm{~mm}$. $5 \mathrm{~mm}$ grafts resulted in $30 \%$ greater relative AP translation than the $9 \mathrm{~mm}$ graft. Furthermore larger grafts were associated with lower meniscal stress and less articular cartilage con- 
tact stress suggesting that wider grafts may provide greater stability to the knee and help to minimise the propagation of degenerative arthritis that is affected by excessive cartilage stress [5].

This idea has been supported by studies suggesting that grafts with diameters equal to or below $8 \mathrm{~mm}$ in diameter were more likely to be revised [6]. One systematic review cited a 6.8 times greater relative risk of failure at or below $8 \mathrm{~mm}$ in width and noted that in the patients younger than 20 years of age grafts larger than $8 \mathrm{~mm}$ decreased failure rates [7]. One retrospective study showed revision was non-existent in patients of all ages with graft size $>8 \mathrm{~mm}$ and that $18.3 \%$ of patients less than 18 years old and with a graft width of less than $8 \mathrm{~mm}$ underwent revision. Further studies have shown larger graft width was correlated with better subjective outcomes [8].

Furthermore, animal models have suggested that more tendon material in the bone tunnels enhanced pull out graft strength at 6 weeks and that a tighter fit significantly increased load to failure. Moreover, more graft material in the tunnel led to a more mature tendon-bone interface histologically translating to initially stronger graft fixation in the early stages of healing [9]. There is therefore potential to achieve this effect by using a wider autograft construct however little is known as to how tighter fit affects healing and pull out strength in humans.

A novel approach to ACL reconstruction using a five-strand hamstring tendon autograft (three-strand Semitendinosus/two-strand Gracilis) has been proposed in an attempt to optimise tendon-bone healing, better restore the functional anatomy of the ACL at its footprints and provide a larger scaffold for the intra-articular remodelling process, with the potential to create a larger, stronger graft and superior knee stability [10] [11]. The shortcomings of this approach include that there must be at least $25 \mathrm{~cm}$ of tendon to form the construct and that the effect of larger bone tunnels on graft healing is unknown.

There is little literature assessing this graft construct clinically. Only one small retrospective study has compared anterior laxity outcomes of Four- and FiveStrand Hamstring Tendon Autografts. This study showed higher stability in the five-strand group. Mean KT-1000 side-to-side differences were $0.44 \mathrm{~mm}$ versus $1.0 \mathrm{~mm}(\mathrm{p}=0.01)$ in the five- and four-strand groups respectively [12] [13]. There are currently no prospective trials in the literature.

This aim of this study was to test the effectiveness of the Five-Strand construct in reducing anterior laxity of ACL deficiency compared to the gold standard Four-Strand repair.

\section{Hypothesis}

A Five-Strand Hamstring Tendon Autograft will reduce the antero-posterior (AP) laxity of the ACL deficient knee more effectively than that of the gold standard Four-Strand Hamstring Tendon Autograft.

\section{Methods}

28 patients referred to a single consultant Orthopaedic Surgeon at our institu- 
tion only were recruited for this research. All patients referred to this surgeon within a six month period for consideration of ACL reconstructive surgery were considered for this trial. All patients included in the trial were diagnosed with ACL rupture by the orthopaedic surgeon leading the enquiry, exhibited a positive Lachmann test and met inclusion criteria (Table 1). Patients suspected of having torn their ipsilateral MCL were not operated until sufficient healing of MCL had been agreed upon by the surgeon. Patients with suspected ipsilateral injuries to the medial and/or lateral menisci were considered for this research and details of arthroscopic treatment of any meniscal injury were recorded intraoperatively. All patients were managed by physiotherapy to ensure that inflammation had sufficiently subsided and an appropriate range of motion was achieved prior to surgery, as determined by the Consulting Surgeon. All patients were informed of the purpose of testing and consented according to a Local Ethics Committee Protocol.

Table 1. Inclusion and exclusion criteria.

\begin{tabular}{ll}
\hline \multicolumn{1}{c}{ Inclusion Criteria } & \multicolumn{1}{c}{ Exclusion Criteria } \\
\hline & - Any associated ipsilateral ligament injury \\
& requiring surgery. \\
- Diagnosis ACL Deficiency by Consultant & - Previous ipsilateral knee ligament injuries. \\
Orthopedic Surgeon. & - Patient refusal of participation. \\
- Positive Lachman Test. & - Inability to consent. \\
- Planned Endoscopic ACL Reconstructive & - Withdrawal from study. \\
$\begin{array}{l}\text { Surgery with Hamstring Autograft } \\
\text { (January 2014 to November 2014). }\end{array}$ & - Current injury or past surgery to contralateral \\
& knee for comparisons to contralateral leg. \\
& Concurrent surgical procedure known to \\
& affect anterior laxity of the knee.
\end{tabular}

ACL reconstructive surgery was performed by the same surgeon in the period January 2014 to November 2014. All procedures were performed under general anaesthesia with local anaesthetic infiltration. Prophylactic intravenous antibiotics were given and an above knee tourniquet was applied.

Semitendinosus and gracilis tendons were harvested via an anteromedial incision. Tendons were stripped of muscle, tubularized and whip-stitched. The Four-Strand construct was formed and the cross-sectional width measured using a graft construct measuring tool. If the construct measured less than $8 \mathrm{~mm}$, a Five-Strand hamstring tendon autograft was prepared. If there was not sufficient length of tendon, or there was difficulty in creating the Five-Strand construct, the Four-Strand construct was used.

\section{Preparation of the Five-Strand Construct}

Firstly, the semitendinosus tendon was sutured to the EndoButton (Smith \& Nephew, London, UK) loop. The opposite end of the semitendinosus was then brought through the EndoButton (Smith \& Nephew, London, UK) loop and folded back on itself to create an equally tensioned 3-strand construct (Figure 1). The two-strand gracilis construct was formed using the conventional method 
for a four-strand construct; the tendon was passed through the EndoButton loop and folded back on itself and equally tensioned [10] [11]. The width of the hamstring autograft at the tibial and femoral ends and the corresponding bony tunnels were recorded.

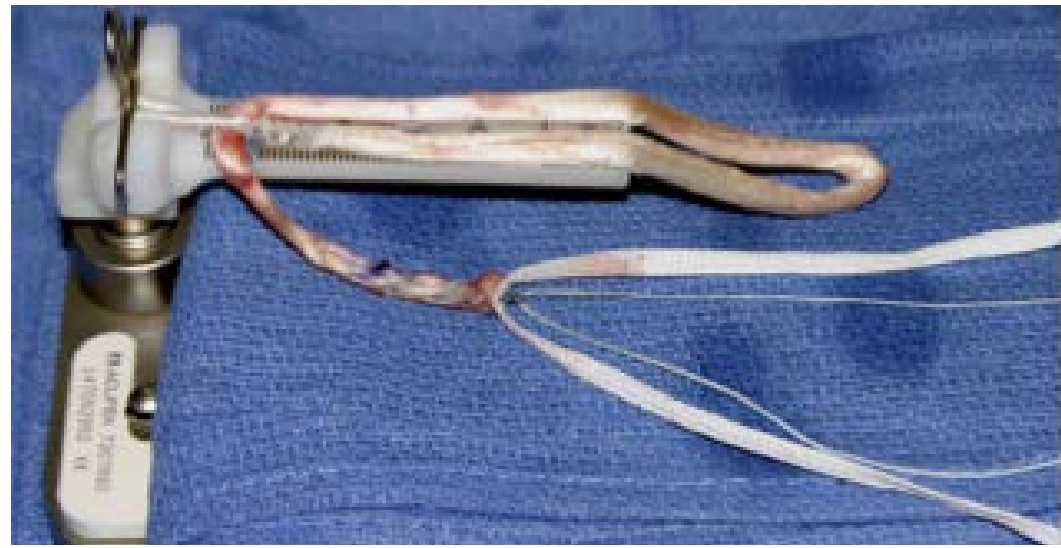

(a)

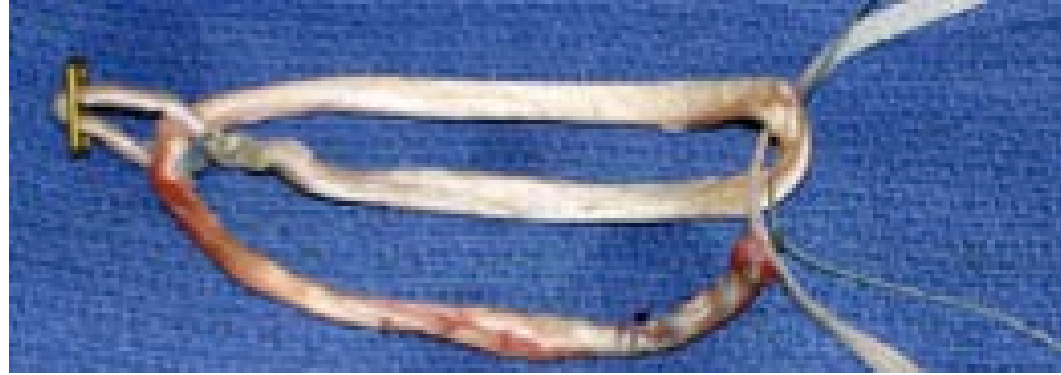

(b)

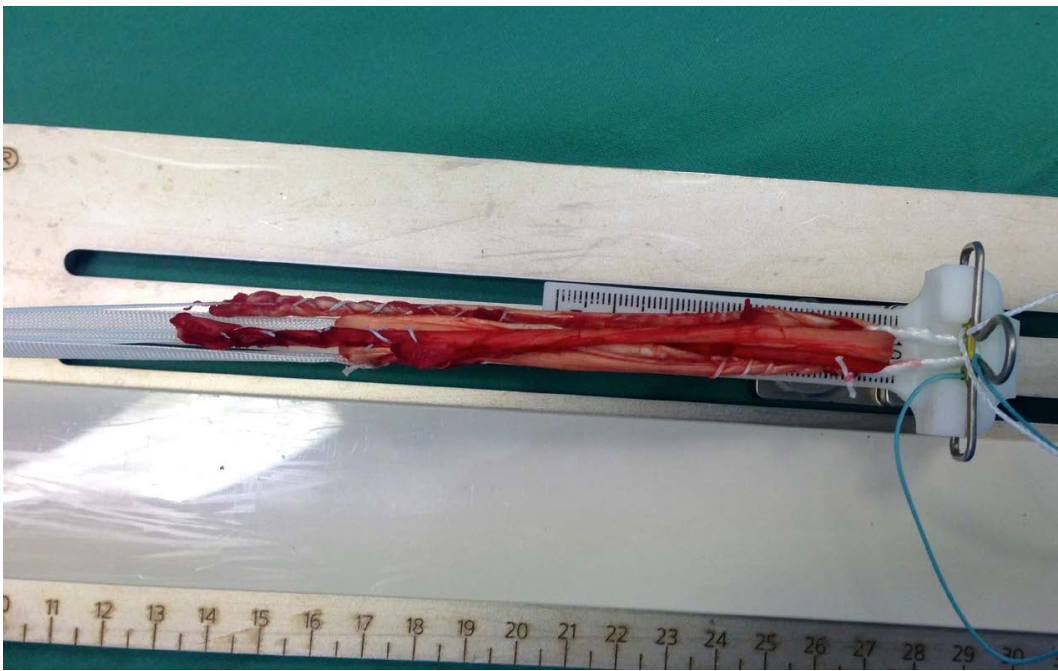

(c)

Figure 1. (a) Three-Strand Semitendinosus Construct is formed by suturing the end of the tendon to the EndoButton loop. (b) The opposite end of the semitendinosus is then brought through the EndoButton loop and folded back on itself to create an equally tensioned Three-Strand construct. (c) Two strand construct is then formed using the conventional method; the tendon is passed through the EndoButton loop, folded back on itself and equally tensioned to create the Five Strand construct. 
The ACL stump was visually identified on the lateral femoral condyle and used as a landmark for femoral tunnel placement. The femoral tunnel was always placed posteriorly to the lateral condylar (Resident's) ridge. The femoral hole was drilled through the anteromedial portal. A $4.5 \mathrm{~mm}$ cannulated Endo Button (Smith \& Nephew, London, UK) reamer was drilled all the way through the lateral femur and then the pre-measured reamer was used to the appropriate tunnel depth. All bone debris was cleared.

The tibial tunnel was drilled using a standard intra-articular jig set at $55^{\circ}$. A guide wire was passed and the residual tibial ACL stump was utilised to gain anatomical positioning. The femoral and tibial tunnels were reamed to the width of the graft. The graft was then passed through the tunnels and tensioned by hand. Femoral fixation was achieved with an EndoButton (Smith \& Nephew, London, UK) and tibial fixation was achieved with an RCI interference screw sized to the tunnel and an extra small bone staple. Any abnormalities of the medial and lateral compartments were identified arthroscopically and recorded. Concurrent intra-articular pathology was treated as deemed appropriate and recorded. All patients were rehabilitated according to a physiotherapy protocol offered by the leading orthopaedic surgeon.

Patients were followed up prospectively at two postoperative time points: 6 weeks (T1) and 12 weeks (T2). These time points were chosen as they represent significant milestones in the graft incorporation process. T1 has previously been shown to be the time point at which the graft is weakest and T2 has been shown to be the time point at which the proliferative phase of graft-bone healing ends and the ligamentization process begins [9] [14] [15] [16]. Furthermore T2 commonly coincides with a return to straight running as dictated by our physiotherapy protocol.

All patients were assessed for clinical stability on Lachman Test by the leading Orthopaedic Surgeon. A single examiner independent to the surgical procedure assessed all patients on KT-1000 preoperatively (T0) using the Maximum Manual Test. Data was acquired strictly adhering to a protocol for both the injured and contralateral knee. This procedure was repeated for patients at 6 (T1) and 12 weeks (T2) postoperatively.

Patient data was dichotomised into Four-Strand and Five-Strand groups. Absolute and side-to-side differences, and change in absolute values and side-side differences were used for analysis. All distributions were tested for normality using D'Agnostino-Pearson Omnibus Test for Normality and the statistical test chosen depending on this result.

Unpaired t-tests and Mann-Whitney Non-Parametric tests were performed to test for differences between the groups for age, time to surgery and graft width.

Repeated Measures ANOVA and Friedman's Non-Parametric Tests with Tukey's and Dunn's Tests for Multiple Comparisons respectively, were used to analyze for significance of change in anterior laxity and side-to-side differences over time for both groups. This was assessed over the three specified time points: Pre-Op (T0), 6 Weeks (T1) and 12 Weeks (T2). 
Unpaired t-tests and Mann-Whitney Non-Parametric tests were performed at all time points between the Four- and Five-Strand groups.

Pearson's and Spearman's Correlation Coefficients were used to quantify correlations between graft widths and both anterior laxity values and side-to-side differences at 6 and 12 weeks, and change in these parameters over time. Correlations were performed between KT-1000 values and Femoral and Tibial Widths for all graft constructs, and for both Four- and Five-Strand subgroups separately. Significance was considered when $\mathrm{p}<0.05$ for all statistical tests.

\section{Results}

\subsection{Clinical Results}

Only one patient exhibited a clinically positive Lachman test at 6 weeks follow up in the Four-Strand group, all other patients' knees were clinically stable on examination. There were no graft failures in either group. Differences in ages and time to surgery were not statistically significant between groups ( $\mathrm{p}=0.20$ and $\mathrm{p}=0.48$ respectively) (Table 2 ). The average width of grafts in the FiveStrand group was $8.4 \pm 0.5 \mathrm{~mm}$ and $8.7 \pm 0.5 \mathrm{~mm}$ at the Femoral and Tibial ends compared to $8.0 \pm 0.6 \mathrm{~mm}$ at both ends for the Four-Strand group (Table 2). Comparison revealed a trend to significance indifference between Femoral graft widths $(\mathrm{p}=0.08)$ and a significant difference was seen between Tibial widths ( $\mathrm{p}$ $<0.01$ ) (Table 2).

Table 2. Demographics and clinical results.

\begin{tabular}{|c|c|c|c|}
\hline & $\begin{array}{l}\text { Four-Strand } \\
\qquad(n=18)\end{array}$ & $\begin{array}{l}\text { Five-Strand } \\
\qquad(n=10)\end{array}$ & $\begin{array}{l}\text { Test Between } \\
\text { Groups p value }\end{array}$ \\
\hline \multicolumn{4}{|l|}{ Demographics } \\
\hline Age (years) & $29.4 .1 \pm 7.2$ & $26.7 \pm 7.6$ & 0.20 \\
\hline Time to Surgery & $16.5 \pm 28.1$ & $4.9 \pm 3.6$ & 0.48 \\
\hline Gender (F, M) & $10 \mathrm{~F}, 8 \mathrm{M}$ & $1 \mathrm{~F}, 9 \mathrm{M}$ & \\
\hline \multicolumn{4}{|l|}{ Width of Graft (mm) } \\
\hline Femoral & $8.0 \pm 0.6$ & $8.4 \pm 0.5$ & 0.08 \\
\hline Tibial & $8.0 \pm 0.6$ & $8.7 \pm 0.5$ & $0.006^{*}$ \\
\hline \multicolumn{4}{|l|}{ Pre-Operative } \\
\hline Positive Lachman & 18 & 10 & \\
\hline Positive Pivot Shift & 16 & 9 & \\
\hline \multicolumn{4}{|l|}{ Post-Operative } \\
\hline Positive Lachman & 1 & Nil & \\
\hline Graft Failure & Nil & Nil & \\
\hline \multicolumn{4}{|l|}{ Concurrent Injury } \\
\hline Concurrent Collateral Injury & $\begin{array}{l}5 \mathrm{MCL} \\
2 \mathrm{LCL}\end{array}$ & $\begin{array}{l}3 \mathrm{MCL}^{*} \\
1 \mathrm{LCL}^{*}\end{array}$ & \\
\hline & 6 Medial & 1 Medial & \\
\hline Concurrent Meniscal Injury & $\begin{array}{l}7 \text { Lateral } \\
1 \text { Both } \\
5 \text { Lateral }\end{array}$ & 1 Medial & \\
\hline Partial Meniscectomy & $\begin{array}{l}3 \text { Medial } \\
1 \text { Both }\end{array}$ & Nil & \\
\hline
\end{tabular}

MCL (Medial Collateral Ligament), LCL (Lateral Collateral Ligament). 


\subsection{Absolute Laxity}

Analysis of absolute anterior laxity illustrated a decrease in mean laxity from the preoperative period to 6 weeks postoperatively in both groups. From 6 - 12 weeks, a slight decrease in laxity was seen in the Four-Strand group and an increase in laxity was seen in the Five-Strand group (Figure 2). Differences in mean anterior laxity on Maximum Manual test were significantly different between graft types at 12 weeks $(\mathrm{p}=0.01)$ in favour of the Four-Strand construct. Differences were not significant preoperatively or at 6 Weeks (Table 3).

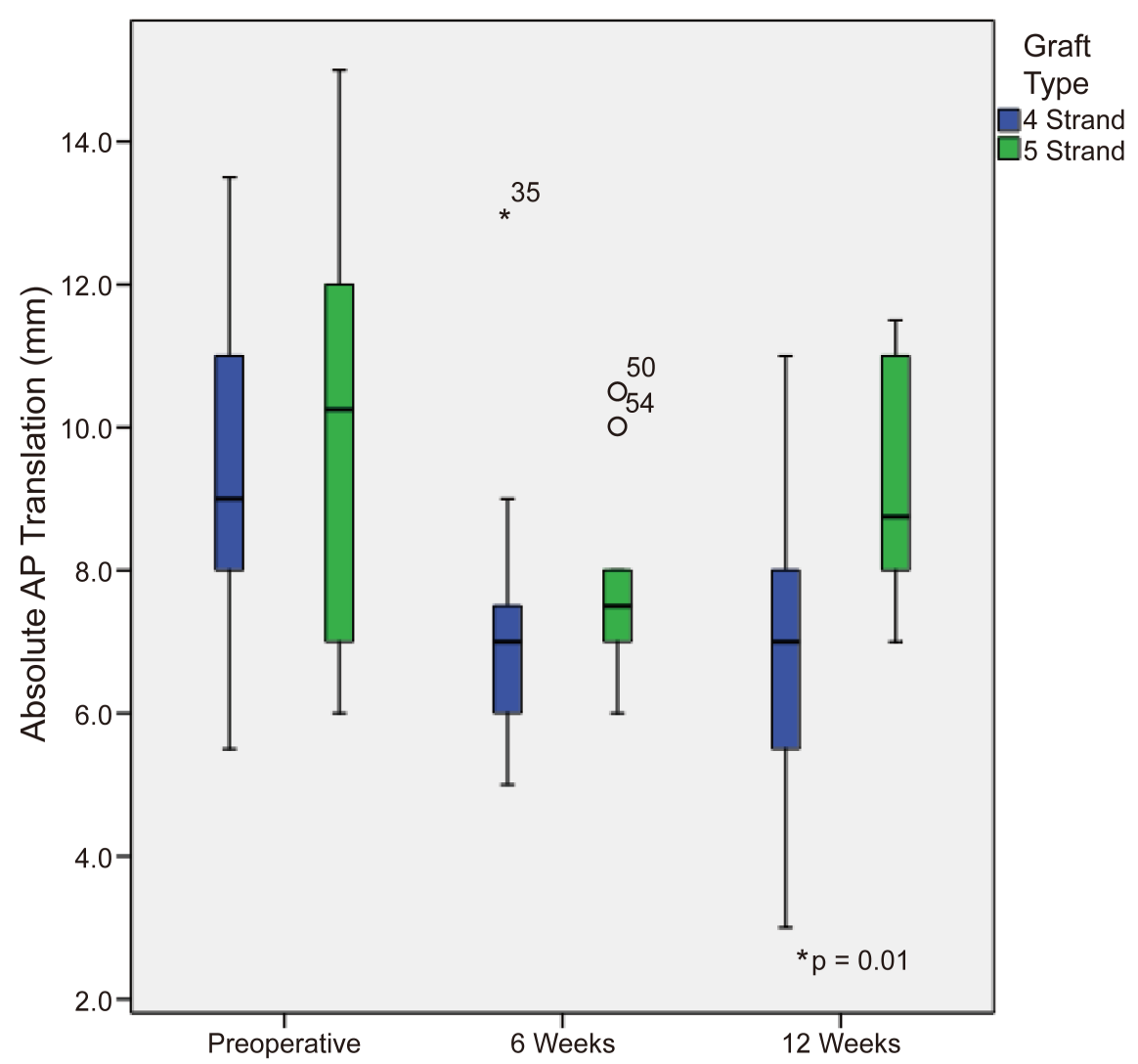

Figure 2. Absolute AP Translation on Maximum Manual Test. Analysis of absolute anterior laxity illustrated a decrease in mean laxity from the preoperative period to 6 weeks postoperatively in both groups. From 6 - 12 weeks, a slight decrease in laxity was seen in the Four-Strand group and an increase in laxity was seen in the Five-Strand group (Figure 2). Differences in mean anterior laxity on Maximum Manual test were significantly different between graft types at 12 weeks $(p=0.01)$ in favour of the Four-Strand construct. Differences were not significant preoperatively or at 6 Weeks (Table 3).

\subsection{Side-to-Side Differences}

Both groups saw a decrease in side-to-side difference from the preoperative period to 6 weeks postoperatively, and an increase in laxity at 12 weeks (Figure 3). Statistically significant differences were seen between graft types for side-to-side difference on Maximum Manual test at 12 weeks $(p=0.01)$ in favour of the Four-Strand construct. A marginally significant result was seen between graft types at 6 weeks $(\mathrm{p}=0.05)$ (Table 3$)$. 
Table 3. Anterior laxity values and statistical comparison between four- and five-strand groups (Mean $\pm \mathrm{SD})$.

\begin{tabular}{lccc}
\hline & Four-Strand & Five-Strand & Test Between Groups p value \\
\hline MM Absolute $(\mathrm{mm})$ & $\boldsymbol{n}=\mathbf{1 8}$ & $\boldsymbol{n}=\mathbf{1 0}$ & \\
Pre-operative & $9.5 \pm 2.7$ & $9.9 \pm 3.1$ & 0.75 \\
6 Weeks & $7.2 \pm 1.8$ & $7.8 \pm 1.5$ & 0.27 \\
12 Weeks & $6.9 \pm 2.3$ & $9.1 \pm 1.7$ & $0.014^{*}$ \\
MM Side to Side (mm) & $\boldsymbol{n}=\mathbf{1 5}$ & $\boldsymbol{n}=\mathbf{9}$ & \\
Pre-operative & $4.7 \pm 2.3$ & $5.2 \pm 2.3$ & 0.60 \\
6 Weeks & $1.7 \pm 2.1$ & $3.6 \pm 2.3$ & 0.05 \\
12 Weeks & $1.9 \pm 2.2$ & $5.1 \pm 3.5$ & $0.011^{*}$ \\
\hline
\end{tabular}

${ }^{*} \mathrm{p}<0.05 ;{ }^{* *} \mathrm{p}<0.01 ;{ }^{* * *} \mathrm{p}<0.001$.

\subsection{Change in Absolute Laxity over Time}

Analysis of change in anterior laxity over time revealed no statistically significant decreases from T0 - T1 in either group (Four-Strand $\mathrm{p}=0.287$, Five Strand $\mathrm{p}=0.18$ ) but a statistically significant increase in the Five-Strand group from 6 12 weeks ( $\mathrm{p}<0.01$ ). When comparing between graft types a statistically significant difference was seen from 6 - 12 weeks in favour of the Four-Strand construct $(\mathrm{p}=0.02)($ Table 4 , Figure 4$)$.

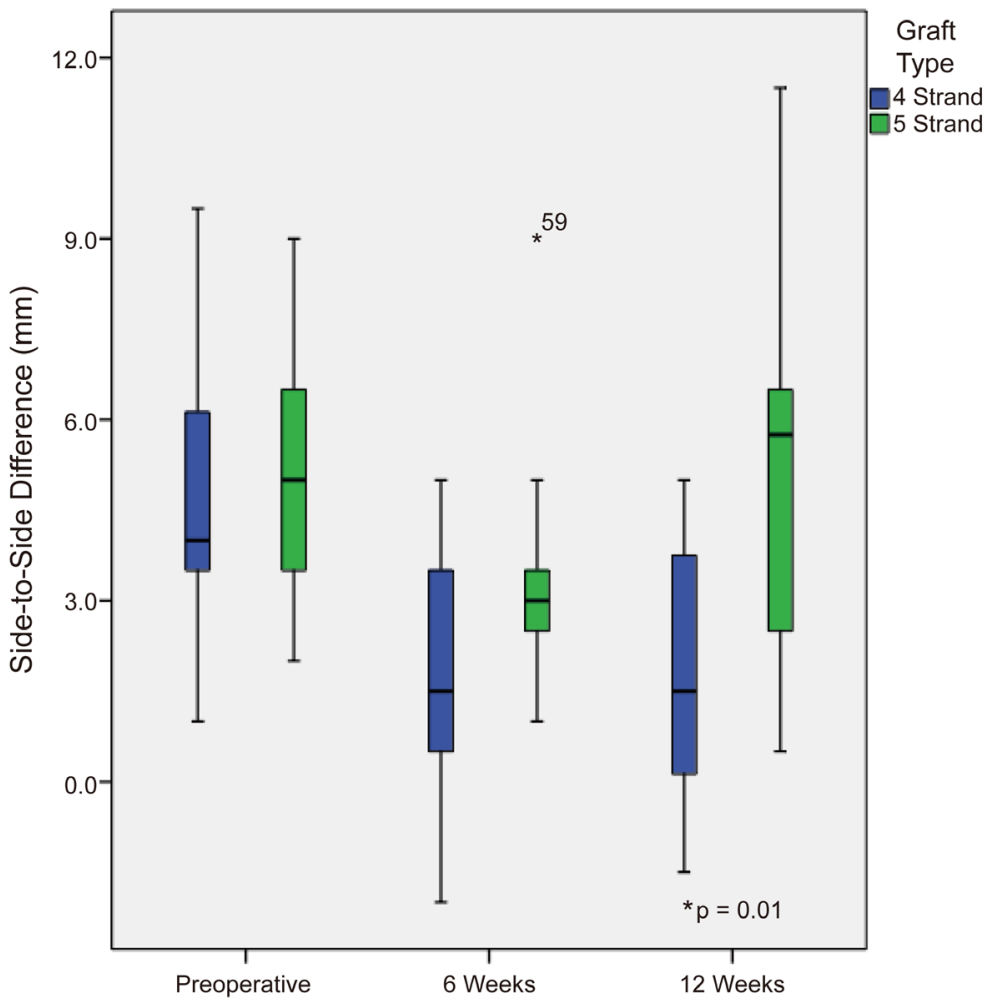

Figure 3. Side to side difference on maximum manual test. Both groups saw a decrease in side-to-side difference from the preoperative period to 6 weeks postoperatively, and an increase in laxity at 12 weeks (Figure 3 ). Statistically significant differences were seen between graft types for side-to-side difference on Maximum Manual test at 12 weeks ( $p=$ 0.01 ) in favour of the Four-Strand construct. A marginally significant result was seen between graft types at 6 weeks $(p=0.05)$ (Table 3$)$. 


\subsection{Change in Side-to-Side Difference over Time}

Analysis of change in side-to-side difference saw a statistically significant decrease in absolute anterior laxity from T0 - T1 in the Four-Strand group ( $\mathrm{p}=$ $0.01)$ but not in the Five-Strand group $(p=0.30)$. There were no significant differences in change from 6 - 12 weeks in either group (Four-Strand $p=0.97$, Five Strand $\mathrm{p}=0.18$ ). Comparison of change in side-to-side difference over time saw no significant difference between the graft types from T0 - T2 (Table 4).

Table 4. Change in anterior laxity and side-to-side difference values and statistical comparison between four- and five-strand groups.

\begin{tabular}{lccc}
\hline & 4 Strand & 5 Strand & $\begin{array}{c}\text { Test Between } \\
\text { Groups p value }\end{array}$ \\
\hline Change Anterior Laxity $(\mathrm{mm})$ & $\boldsymbol{n}=18$ & $\boldsymbol{n}=10$ & \\
PreOp - 6 Weeks & & & 0.89 \\
Mean \pm SD & $-2.3 \pm 2.9$ & $-2.2 \pm 3.5$ & \\
p value & 0.29 & 0.18 & $0.016^{*}$ \\
6 - 12 Weeks & $-0.3 \pm 1.9$ & $1.4 \pm 0.9$ & \\
Mean \pm SD & $>0.99$ & $0.003^{* *}$ & \\
p value & $\boldsymbol{n}=15$ & $\boldsymbol{n}=9$ & 0.37 \\
Change in Side-to-Side Difference (mm) & & & \\
PreOp - 6 Weeks & $-3.0 \pm 3.1$ & $-1.6 \pm 3.0$ & \\
Mean \pm SD & $0.006^{* *}$ & 0.30 & 0.40 \\
p value & & & \\
6 - 12 Weeks & & & \\
Mean \pm SD & $0.2 \pm 3.3$ & $1.6 \pm 2.5$ & \\
p value & 0.97 & 0.18 & \\
\hline
\end{tabular}

${ }^{*} \mathrm{p}<0.05 ;{ }^{* *} \mathrm{p}<0.01 ;{ }^{* *} \mathrm{p}<0.001$.

\section{Correlations}

No significant correlations were seen between graft width at Femoral and Tibial ends, and AP Translation or Side-to-Side Difference at any time point (Table 5). Furthermore, no significant correlations were seen between graft widths and change in laxity over time. This was consistent for when all graft types were considered together and when Four-and Five-Strand grafts were analysed separately. There was a trend to significance in the Five-Strand group suggesting that as Femoral graft width increased in this group, change in anterior laxity from $6-12$ weeks increased (Pearson $r=0.555, \mathrm{p}=0.10$ ) (Table 6).

\section{Discussion}

Clinically, both groups illustrated evidence of anterior stability by 6 weeks with only one patient in the Four-Strand group illustrating a positive Lachman Test. There were no graft failures in the first 12 weeks. Instrumented testing of AP 


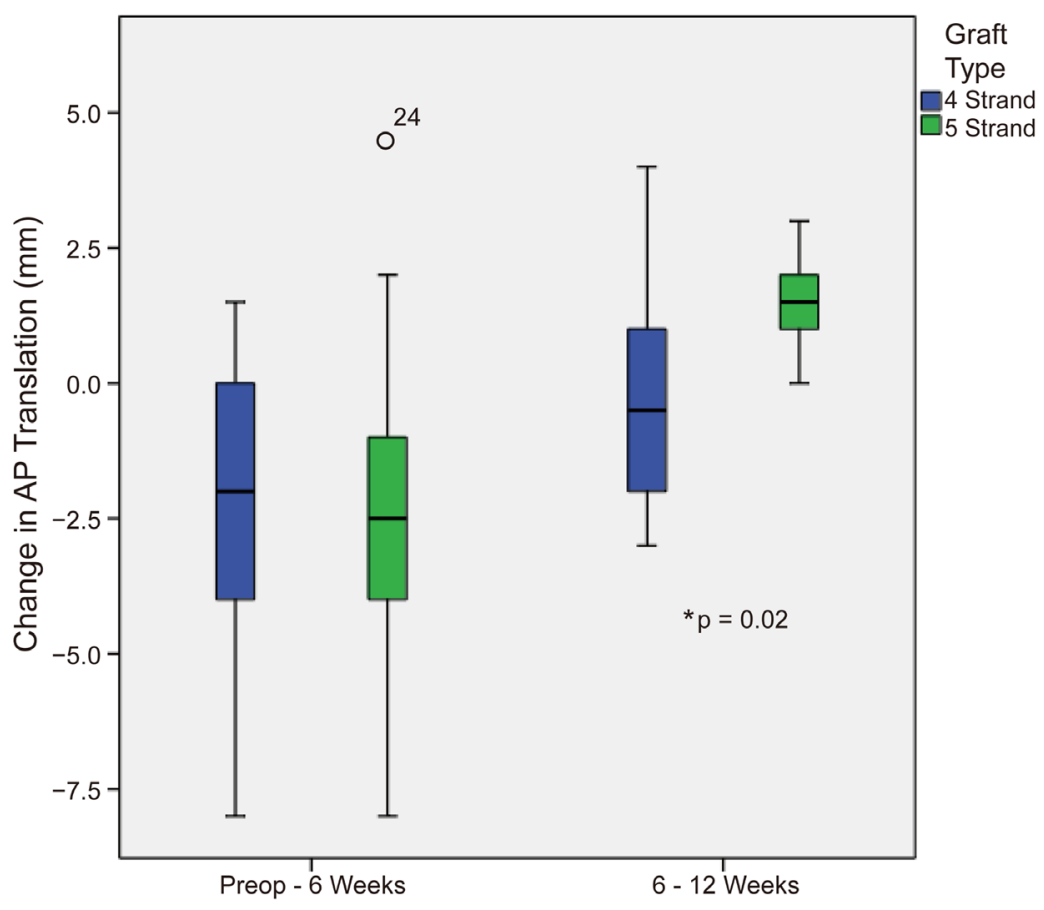

Figure 4. Analysis of change in anterior laxity over time revealed no statistically significant decreases from T0 - T1 in either group (Four-Strand $p=0.287$, Five Strand $p=0.18$ ) but a statistically significant increase in the Five-Strand group from $6-12$ weeks $(\mathrm{p}<$ 0.01 ). When comparing between graft types a statistically significant difference was seen from 6 - 12 weeks in favour of the Four-Strand construct $(\mathrm{p}=0.02)$ (Table 4).

Table 5. Correlations between graft widths at tibial and femoral ends, and anterior laxity and side-to-side differences. Data presented as correlation coefficient with significance value in parentheses.

\begin{tabular}{ccc}
\hline & AP Translation & Side-to-Side Difference \\
\hline All Grafts & $\boldsymbol{n}=\mathbf{2 8}$ & $\boldsymbol{n}=\mathbf{2 4}$ \\
Tibial & $-0.09(0.66)$ & $0.06(0.77)$ \\
T1 & $0.11(0.59)$ & $0.29(0.17)$ \\
T2 & & $-0.10(0.63)$ \\
Femoral & $-0.20(0.31)$ & $0.15(0.46)$ \\
T1 & $0.05(0.81)$ & $\boldsymbol{n}=\mathbf{9}$ \\
T2 & $\boldsymbol{n}=10$ & $0.12(0.75)$ \\
Five-Strand & $-0.33(0.35)$ & $-0.32(0.41)$ \\
Tibial & $-0.27(0.45)$ & \\
T1 & & $0.05(0.87)$ \\
T2 & $-0.48(0.16)$ & $-0.35(0.35)$ \\
Femoral & $-0.13(0.72)$ & $\boldsymbol{n}=15$ \\
T1 & $\boldsymbol{n}=18$ & \\
T2 & & $-0.38(0.16)$ \\
Four-Strand & $-0.20(0.20)$ & $0.29(0.29)$ \\
Tibial & $-0.13(0.61)$ & $-0.38(0.16)$ \\
T1 & $-0.20(0.42)$ & $0.29(0.29)$ \\
T2 & $-0.13(0.62)$ & \\
Femoral & & \\
T1 & & \\
T2 & & \\
\hline & & \\
\hline & & \\
\hline
\end{tabular}


Table 6. Correlations between graft widths at tibial and femoral ends and change in laxity and side-to-side difference. Data presented as correlation coefficient with significance value in parentheses.

\begin{tabular}{|c|c|c|}
\hline & Change in AP Translation & Change in Side-to-Side Difference \\
\hline All Grafts & $n=28$ & $n=24$ \\
\hline \multicolumn{3}{|l|}{ Tibial } \\
\hline $\mathrm{T} 0-\mathrm{T} 1$ & $-0.05(0.79)$ & $0.06(0.80)$ \\
\hline $\mathrm{T} 1-\mathrm{T} 2$ & $0.28(0.14)$ & $0.22(0.31)$ \\
\hline \multicolumn{3}{|l|}{ Femoral } \\
\hline $\mathrm{T} 0-\mathrm{T} 1$ & $-0.13(0.50)$ & $-0.05(0.81)$ \\
\hline $\mathrm{T} 1-\mathrm{T} 2$ & $0.28(0.14)$ & $0.20(0.35)$ \\
\hline Five-Strand & $n=10$ & $n=9$ \\
\hline \multicolumn{3}{|l|}{ Tibial } \\
\hline $\mathrm{T} 0-\mathrm{T} 1$ & $-0.25(0.48)$ & $-0.32(0.40)$ \\
\hline $\mathrm{T} 1-\mathrm{T} 2$ & $0.06(0.87)$ & $-0.49(0.18)$ \\
\hline \multicolumn{3}{|l|}{ Femoral } \\
\hline $\mathrm{T} 0-\mathrm{T} 1$ & $-0.50(0.14)$ & $-0.45(0.22)$ \\
\hline $\mathrm{T} 1-\mathrm{T} 2$ & $0.56(0.096)$ & $-0.39(0.30)$ \\
\hline Four-Strand & $n=18$ & $n=15$ \\
\hline \multicolumn{3}{|l|}{ Tibial } \\
\hline $\mathrm{T} 0-\mathrm{T} 1$ & $0.01(0.96)$ & $0.17(0.55)$ \\
\hline $\mathrm{T} 1-\mathrm{T} 2$ & $0.07(0.76)$ & $0.36(0.19)$ \\
\hline \multicolumn{3}{|l|}{ Femoral } \\
\hline T0 - T1 & $0.01(0.96)$ & $0.17(0.55)$ \\
\hline $\mathrm{T} 1-\mathrm{T} 2$ & $0.07(0.76)$ & $0.36(0.19)$ \\
\hline
\end{tabular}

Translation on KT-1000 however revealed a greater decrease in side-to-side difference in the Four-Strand group at 6 weeks and a greater increase in laxity at 12 weeks in the Five-Strand group. This trend was evident also on analysis of absolute laxity values. These results support the superiority of the Four-Strand hamstring tendon autograft by 12 weeks maintaining a mean side-to-side difference of $<3 \mathrm{~mm}(1.9 \pm 2.2 \mathrm{~mm})$ compared to the Five-Strand group $(5.1 \pm 3.1 \mathrm{~mm})$. This result is contrary to what has been reported in the literature, Prodromos et al (2005) reported a mean side-to-side difference on KT-1000 of $1.0 \mathrm{~mm}$ for the Five-Strand group and $0.44 \mathrm{~mm}$ for the Four-Strand group $(\mathrm{p}=0.01)(11)$.

The advantage of prospective longitudinal data is that a preoperative laxity adjusted comparison of the effect of the graft on reducing laxity over time can 
be made. Changes from preoperative absolute laxity values to that at 6 weeks saw no significant differences between the graft types. However, changes in side-to- side difference from T0 - T1 were significant in the Four Strand group $(\mathrm{p}<0.01)$. Significant changes in both absolute values and side-to-side differences for the Four-Strand group and a significant increase in absolute laxity from $6-12$ weeks in the Five-Strand group illustrated superiority in the Four-Strand group in reducing and maintain lower laxity in the immediate postoperative period.

Furthermore, although significant correlations between graft width, and both measures of anterior laxity postoperatively and changes in these measures over time were not found, an association between graft width and increasing instability from T1 - T2 in the Five-Strand graft approached significance (Pearson $r=$ $0.555, \mathrm{p}=0.10$ ). This corresponded with a highly significant mean increase in laxity in the Five-Strand group from $6-12$ weeks (Mean Difference $1.4 \pm 0.9$ $\mathrm{mm}, \mathrm{p}<0.01$ ) and a statistically significant difference between the graft types ( $\mathrm{p}$ $=0.02$ ) confirming this relationship as an important finding and further suggesting that an upper limit for graft width exists before it becomes disadvantageous to anterior stability of the knee.

There are a number of possible explanations for this. Firstly, the rationale for the five-strand construct is centred on maximising graft width in patients with small hamstring diameters. In forming the Five-Strand graft, an increase in width and a potentially larger amount of tendon material in the tibial tunnel is achieved leading to a more mature tendon-bone interface histologically and therefore initially stronger graft fixation in the early stages of healing. This is consistent with evidence from animal studies [9]. It may be the case however that an increase in tendon material in the bone tunnel is detrimental to tendon-bone healing after 6 weeks in humans, as illustrated by significant differences in anterior laxity and side-to-side differences at 12 weeks, and change in anterior laxity from $6-12$ weeks in favour of the Four-Strand group. Histologi$\mathrm{cal}$ analysis of bone healing between groups would shed more light on this question and should be considered for further research.

Cadaveric studies have established that commonly used autograft sizes do not correlate with either area of the native footprint of the ACL, or the size of the lateral wall of femoral intercondylar notch and tibial plateau. Therefore these results may illustrate that increasing the diameter of the graft in patients with small hamstring tendons may create bone tunnels that are too large relative to surrounding anatomy [17] [18]. Current evidence has suggested that graft sizes $<8 \mathrm{~mm}$ are more likely to fail, particularly in younger patients (6). As mean graft widths were greater than $8 \mathrm{~mm}$ in both groups and a trend was evident suggesting larger graft widths were disadvantageous to maintaining levels of laxity from 6 - 12 weeks in the Five-Strand group, it is possible that there is a finer balance in achieving an optimal graft width than previously thought. That is, the width of the graft should be large enough to avoid failure but not so large that it is potentially detrimental to tendon-bone healing and antero-posterior stability of the 
knee. The relationship between optimal graft size, area of coverage of native anatomical footprints of the ACL and anterior stability of the knee should be considered for further research.

There are a number of important considerations with regards to limitations of this study. Firstly, this was designed as a short-term study to closely analyse the differences between graft constructs during crucial parts of the immediate phase remodelling and incorporation of the new graft into the surrounding bone. Animal and human studies in sheep have shown that strength of the graft increases with time [19] [20], however data from later time points is needed to answer the question as to how anterior stability will differ between these two groups up to 2 - 5 years post operatively and how graft width will be associated with graft failure rates.

Secondly, this surgical method dictated a cut off point for forming the FiveStrand construct of less than or equal to $8 \mathrm{~mm}$ width and therefore these results are most relevant for this surgical method. A greater element of generalizability could be achieved by randomisation between graft types, which would allow for a potentially greater disparity in graft widths between the groups and elimination of selection bias.

Thirdly, ACL reconstructive surgery is a biomechanically complex procedure and key variables include anatomic positioning of tunnels, graft tensioning, variability in patient anatomy (particularly relationships between graft and native ACL footprint sizes), physiological characteristics affecting tendon-bone healing, concurrent meniscal and subsequent meniscal procedures, and general surgical variability [21] [22]. Tunnel positioning is known to have a significant impact on tensioning properties and healing of the graft and although consistent surgical methods were used to assure anatomic positioning using the anteromedial portal, variability may have had an effect on results [23] [24] [25].

Lastly, the sample size of this trial was small and repeated trials with larger samples in larger centres will be required to confirm the findings of this trial and enhance its generalizability.

\section{Conclusion}

This study illustrated that there was no benefit to use a Five-Strand Hamstring Tendon Autograft when compared to the gold standard Four-Strand Repair, specifically with regards to anterior stability of the knee in the first 12 weeks postoperatively.

\section{References}

[1] Hamner, D.L., Brown, C.H., Steiner, M.E., Hecker, A.T. and Hayes, W.C. (1999) Hamstring Tendon Grafts for Reconstruction of the Anterior Cruciate Ligament: Biomechanical Evaluation of the Use of Multiple Strands and Tensioning Techniques. The Journal of Bone and Joint Surgery American Volume, 81, 549-557. https://doi.org/10.2106/00004623-199904000-00013

[2] Middleton, K.K., Muller, B., Araujo, P.H., Fujimaki, Y., Rabuck, S.J., Irrgang, J.J., et al. (2014) Is the Native ACL Insertion Site "Completely Restored” Using an Indivi- 
dualized Approach to Single-Bundle ACL-R? Knee Surgery, Sports Traumatology, Arthroscopy. Official Journal of the ESSKA, 23, 2145-2150.

[3] Erquicia, J.I., Gelber, P.E., Doreste, J.L., Pelfort, X., Abat, F. and Monllau, J.C. (2013) How to Improve the Prediction of Quadrupled Semitendinosus and Gracilis Autograft Sizes with Magnetic Resonance Imaging and Ultrasonography. The American Journal of Sports Medicine, 41, 1857-1863. https://doi.org/10.1177/0363546513479340

[4] Robinson, J., Stanford, F.C., Kendoff, D., Stuber, V. and Pearle, A.D. (2009) Replication of the Range of Native Anterior Cruciate Ligament Fiber Length Change Behavior Achieved by Different Grafts: Measurement Using Computer-Assisted Navigation. The American Journal of Sports Medicine, 37, 1406-1411.

https://doi.org/10.1177/0363546509331941

[5] Westermann, R.W., Wolf, B.R. and Elkins, J.M. (2013) Effect of ACL Reconstruction Graft Size on Simulated Lachman Testing: A Finite Element Analysis. The Iowa Orthopaedic Journal, 33, 70-77.

[6] Magnussen, R.A., Lawrence, J.T., West, R.L., Toth, A.P., Taylor, D.C. and Garrett, W.E. (2012) Graft Size and Patient Age Are Predictors of Early Revision after Anterior Cruciate Ligament Reconstruction with Hamstring Autograft. Arthroscopy: The Journal of Arthroscopic \& Related Surgery. Official Publication of the Arthroscopy Association of North America and the International Arthroscopy Association, 28, 526-531.

[7] Conte, E.J., Hyatt, A.E., Gatt, C.J. and Dhawan, A. (2014) Hamstring Autograft Size Can Be Predicted and Is a Potential Risk Factor for Anterior Cruciate Ligament Reconstruction Failure. Arthroscopy. The Journal of Arthroscopic \& Related Surgery. Official Publication of the Arthroscopy Association of North America and the International Arthroscopy Association, 30, 882-890.

[8] Mariscalco, M.W., Flanigan, D.C., Mitchell, J., Pedroza, A.D., Jones, M.H., Andrish, J.T., et al. (2013) The Influence of Hamstring Autograft Size on Patient-Reported Outcomes and Risk of Revision after Anterior Cruciate Ligament Reconstruction: A Multicenter Orthopaedic Outcomes Network (MOON) Cohort Study. Arthroscopy: The Journal of Arthroscopic \& Related Surgery: Official Publication of the Arthroscopy Association of North America and the International Arthroscopy Association, 29, 1948-1953.

[9] Greis, P.E., Burks, R.T., Bachus, K. and Luker, M.G. (2001) The Influence of Tendon Length and Fit on the Strength of a Tendon-Bone Tunnel Complex. A Biomechanical and Histologic Study in the Dog. The American Journal of Sports Medicine, 29, 493-497.

[10] Brown, C.H. (2014) Anatomic ACL Reconstruction: What Is It and How Do We Achieve It? 16th ESSKA (European Society of Sports Traumatology, Knee Surgery and Arthroscopy) Congress, Amsterdam, 16 May 2014.

[11] Lavery, K.P., Rasmussen, J.F. and Dhawan, A. (2014) Five-Strand Hamstring Autograft for Anterior Cruciate Ligament Reconstruction. Arthroscopy Techniques, 3, e423-e426.

[12] Bach, B.R., Jones, G.T., Hager, C.A., Sweet, F.A. and Luergans, S. (1995) Arthrometric Results of Arthroscopically Assisted Anterior Cruciate Ligament Reconstruction Using Autograft Patellar Tendon Substitution. The American Journal of Sports Medicine, 23, 179-185. https://doi.org/10.1177/036354659502300210

[13] Prodromos, C. and Joyce, B. (2005) Five-Strand Hamstring Anterior Cruciate Ligament Reconstruction: Presentation of a New Technique with Better Stability at 7 to 9-Year Follow up than 4 Strand. Techniques in Orthopaedics, 20, 192-193. 
https://doi.org/10.1097/01.bto.0000177264.50076.b2

[14] Goradia, V.K., Rochat, M.C., Kida, M. and Grana, W.A. (2000) Natural History of a Hamstring Tendon Autograft Used for Anterior Cruciate Ligament Reconstruction in a Sheep Model. The American Journal of Sports Medicine, 28, 40-46.

[15] Butler, D.L., Grood, E.S., Noyes, F.R., Olmstead, M.L., Hohn, R.B., Arnoczky, S.P., et al. (1989) Mechanical Properties of Primate Vascularized vs. Nonvascularized Patellar Tendon Grafts; Changes over Time. Journal of Orthopaedic Research: Official Publication of the Orthopaedic Research Society, 7, 68-79. https://doi.org/10.1002/jor.1100070110

[16] Janssen, R.P.A. and Scheffler, S.U. (2014) Intra-Articular Remodelling of Hamstring Tendon Grafts after Anterior Cruciate Ligament Reconstruction. Knee Surgery, Sports Traumatology, Arthroscopy, 22, 2102-2108. https://doi.org/10.1007/s00167-013-2634-5

[17] Iriuchishima, T., Ryu, K., Yorifuji, H., Aizawa, S. and Fu, F.H. (2014) Commonly Used ACL Autograft Areas Do Not Correlate with the Size of the ACL Footprint or the Femoral Condyle. Knee Surgery, Sports Traumatology, Arthroscopy: Official Journal of the ESSKA, 22, 1573-1579. https://doi.org/10.1007/s00167-013-2595-8

[18] Iriuchishima, T., Shirakura, K., Yorifuji, H., Aizawa, S. and Fu, F.H. (2013) Size Comparison of ACL Footprint and Reconstructed Auto Graft. Knee Surgery, Sports Traumatology, Arthroscopy: Official Journal of the ESSKA, 21, 797-803. https://doi.org/10.1007/s00167-012-1949-y

[19] Neddermann, A., Willbold, E., Witte, F., Hurschler, C., Hankemeier, S., Stubig, T., et al. (2009) Tunnel Widening after Anterior Cruciate Ligament Reconstruction: An Experimental Study in Sheep. The American Journal of Sports Medicine, 37, 16091617. https://doi.org/10.1177/0363546509332251

[20] Hamada, M., Shino, K., Horibe, S., Mitsuoka, T., Toritsuka, Y. and Nakamura, N. (2005) Changes in Cross-Sectional Area of Hamstring Anterior Cruciate Ligament Grafts as a Function of Time Following Transplantation. Arthroscopy. The Journal of Arthroscopic \& Related Surgery. Official Publication of the Arthroscopy Association of North America and the International Arthroscopy Association, 21, 917-922.

[21] Seon, J.K., Gadikota, H.R., Kozanek, M., Oh, L.S., Gill, T.J. and Li, G. (2009) The Effect of ACL Reconstruction on Kinematics of the Knee with Combined ACL Injury and Subtotal Medial Meniscectomy-An in Vitro Robotic Investigation. Arthroscopy: The Journal of Arthroscopic \& Related Surgery: Official Publication of the Arthroscopy Association of North America and the International Arthroscopy Association, 25, 123-130.

[22] Musahl, V., Citak, M., O’Loughlin, P.F., Choi, D., Bedi, A. and Pearle, A.D. (2010) The Effect of Medial versus Lateral Meniscectomy on the Stability of the Anterior Cruciate Ligament-Deficient Knee. The American Journal of Sports Medicine, 38, 1591-1597. https://doi.org/10.1177/0363546510364402

[23] Dargel, J., Gotter, M., Mader, K., Pennig, D., Koebke, J. and Schmidt-Wiethoff, R. (2007) Biomechanics of the Anterior Cruciate Ligament and Implications for Surgical Reconstruction. Strategies in Trauma and Limb Reconstruction, 2, 1-12. https://doi.org/10.1007/s11751-007-0016-6

[24] Ekdahl, M., Nozaki, M., Ferretti, M., Tsai, A., Smolinski, P. and Fu, F.H. (2009) The Effect of Tunnel Placement on Bone-Tendon Healing in Anterior Cruciate Ligament Reconstruction in a Goat Model. The American Journal of Sports Medicine, 37, 1522-1530. https://doi.org/10.1177/0363546509332503

[25] Musahl, V., Plakseychuk, A., VanScyoc, A., Sasaki, T., Debski, R.E., McMahon, P.J., et al. (2005) Varying Femoral Tunnels between the Anatomical Footprint and Iso- 
metric Positions: Effect on Kinematics of the Anterior Cruciate Ligament-Reconstructed Knee. The American Journal of Sports Medicine, 33, 712-718.

https://doi.org/10.1177/0363546504271747

Submit or recommend next manuscript to SCIRP and we will provide best service for you:

Accepting pre-submission inquiries through Email, Facebook, LinkedIn, Twitter, etc. A wide selection of journals (inclusive of 9 subjects, more than 200 journals)

Providing 24-hour high-quality service

User-friendly online submission system

Fair and swift peer-review system

Efficient typesetting and proofreading procedure

Display of the result of downloads and visits, as well as the number of cited articles

Maximum dissemination of your research work

Submit your manuscript at: http://papersubmission.scirp.org/

Or contact ojo@scirp.org 